\title{
JOÃO URSO: DO RISO SOLITÁRIO À SOLIDÃO DA INCOMUNICABILIDADE
}

\section{Edilma Acioli Bomfim (*)}

\section{A loucura: entre o demonismo e a irrisão}

$\mathrm{Na}$ relação entre o criador e a obra de arte, Jung demarca os modos de criação poética, estabelecendo duas propostas ou motivos pelos quais o artista se expressa: o modo "psicológico e o visionário". No modo psicológico, o poeta utiliza conteúdos que se movem nos espaços da consciência humana, explorando lições de vida, dramas passionais, comoções, alegrias, dores, alçando experiências do lugar comum ao nível da representação poética. Jung afirma que, se se chama "tal criação artística de psicológica é pelo fato de ela mover-se sempre nos limites do que psicologicamente é compreensível e assinalável". ' Já o modo de criação visionário explora conteúdos que nos são desconhecidos. Diante de textos dessa natureza, o leitor é surpreendido, sente-se desconfiado, receoso, ou o que é mais significativo, chega a "experimentar repugnância," uma vez que o tema desses escritos é extraído das obscuridades profundas do inconsciente. A expressão dessa essencialidade desconhecida constitui o caráter estranho e perturbador do modo visionário de criação artística. Jung ainda acrescenta que os conteúdos estranhos que se apresentam na literatura visionária são, entre outros aspectos, representações das imperfeições psíquicas, anomalias e doenças que também fazem parte da natureza humana.

Esse argumento de Jung, chamando a atenção para a etiologia do texto poético, esclarece a perturbação, estranheza e inquietação que sentimos quando nos deparamos com a leitura das narrativas de Breno Accioly. O conto "João Urso"2, que abre a coletânea do mesmo nome, já inicia esse processo de mergulho no inconsciente profundo como

(*) É professora do Programa de Pós-Graduação em Letras e Lingüística da Universidade Federal de Alagoas.

1 JUNG, C. G. O espírito na arte e na ciência. Trad. Dora Ferreira da Silva e Rubem Siqueira Bianchi. Petrópolis: Vozes, 1985, p.78.

2 ACCIOLY, Breno. João Urso. 4. ed. Rio de Janeiro: Civilização Brasileira, 1995. 
quem, de fato, pretende, em uma rigidez progressiva e monstruosa, representar o inconsciente do protagonista a partir de um processo de crescente decomposição mental. A história de João Urso, contada por um narrador onisciente intruso, invade as sutilezas da mente da personagem, revelando um mundo de estranheza e de insanidade; um mundo lúgubre e fantasmagórico que constitui o leitmotiv da coletânea como um todo. A perturbação provocada pela gargalhada imprópria e aterrorizante de João Urso, que "rasgava a garganta, abria fortemente o talho da boca", ${ }^{3}$ expõe o drama das suas entranhas e gera, pelo eco apavorante desse riso, todas as demais histórias trágicas narradas nos textos subseqüentes. Esse conto constitui o fio condutor que engendra a aparição, nas diversas narrativas, de todas as demais personagens mutiladas em seus afetos e psiquismos; o narrador desata a ponta do novelo, e a linha da vida das criaturas ficcionais rola e se entrelaça em vários nós, barreiras individuais de cada uma das personagens.

O conto João Urso relata a história de um núcleo familiar composto por uma mãe que não tem nome, nem rosto, constituindo uma figura abandonada, sofrida e carente ao lado do filho João Urso, estranho, disforme, repugnante, com "o peito atrofiado, as mãos pequenas, a cabeça descomunal", ${ }^{4}$ rindo assustadoramente nas situações mais inusitadas. Ser profundamente solitário que, irônica e paradoxalmente, é temido, odiado e até enclausurado pela extemporaneidade do seu riso.

Ele mesmo nem sabia explicar. Quando via, era a mãe gritando-Ihe aos ouvidos, contrariada, aborrecida por querer saber a origem daqueles esparsos, inexplicáveis risos.[...] A boca se the rasgava mostrando aqueles dentes cheios de limo, as bochechas se arredondavam e cheias espremiam os olhos, transformavam o rosto de João Urso, enquanto ele ria aquela oculta e misteriosa satisfação. ${ }^{5}$

A ambivalência do riso assustador instaura um sentido perverso, alienado e alienante para a personagem central, fazendo dessa criatura insana um ser sem lugar que desliza entre antinomias:

3 p.29. A partir daqui todas as referências ao conto João Urso aparecerão $\mathrm{em}$ notas de rodapé indicadas apenas pelo número da página.

p. 25 .

p.21. 
dócil mas assustador; altamente triste, mas gargalhando; rindo profundamente e sendo temido. O narrador joga com essa idéia paradoxal para mostrar, a nosso ver, a psique desestruturada da personagem, representando-a através desse riso "que ninguém compreendia, o que fez muita gente chamar-lhe de maluco". 6 Intensificando o aspecto insano da mente de João Urso, a sua caracterização psíquica desintegrada é tecida através de imagens que reportam ao inconsciente primitivo, como: boca rasgada, limo nos dentes, bochechas espremendo os olhos e outras que se articulam na narrativa.

Pai e mãe são, simultaneamente, mitificados e não nomeados no texto. Mas as ações e, especificamente, a prolongada ausência do pai determinam a composição da personagem denominada mãe e, principalmente, de João Urso. Sobre essa constante ausência, o narrador conta que o pai "de repente partia, sem avisar, deixando no olhar da mãe de João Urso aquela saudade tão repetida, uma saudade que se normalizava pelas repetições"?

\section{Faetonte: o mito da orfandade}

Jung afirma que a arte visionária exprime, através de figuras mitológicas específicas, os arquétipos em ebulição nas profundezas inconscientes. Dessa forma, entendemos que, ao construir uma personagem profundamente marcada pela ausência do pai, - "quando conheceu o pai já sabia falar, todos os dentes já lhe haviam nascido", - o narrador de João Urso (re) toma o mito de Faetonte, símbolo da orfandade, herói que desconhecia a própria procedência divina e, consequientemente, não sabia o nome do pai.

Conta a lenda que Faetonte era filho de Hélio, o deus Sol, e que fora educado apenas por sua mãe, a ninfa Climene, em total desconhecimento de quem era o seu pai. Ao chegar à adolescência, os amigos zombavam dessa ausência paterna e da idéia de o jovem ser filho de um deus até então sem nome. Acabrunhado, sofrido, desejoso de conhecer a sua real paternidade, Faetonte insiste para que a mãe revele a identidade do pai: " - Se sou, na verdade, de origem celeste

\footnotetext{
6 p. 21.

7 p. $28-9$.

8 p. 28.
} 
dá-me, minha mãe, uma prova disso, que me assegure o direito de reclamar a honra." Climene, tomando o Sol por testemunha, assegura-lhe que seu pai é Hélio. Feliz e orgulhoso da sua origem, Faetonte parte em busca do pai; percorre caminhos íngremes, scala longas e árduas encostas, e pára afinal, ofuscado pelo brilho exaustivo do palácio paterno "reluzente de ouro e de pedras preciosas, com tetos de marfim polido e as portas de prata." esmeraldas, Hélio, que tudo vê, divisou na luz o próprio filho e, para que ele pudesse se aproximar, reduziu o esplendor do palácio e disse a Faetonte: - "Meu filho, mereces não ser repudiado e confirmo o que tua mãe te disse. Para pôr fim às tuas dúvidas, pede o que quiseres, e tua vontade será satisfeita." 11 Faetonte pediu para ser o condutor da carruagem do Sol pelo firmamento, o que fez Hélio arrepender-se da promessa feita. Como Faetonte não desistisse do pedido e cobrasse a promessa feita como forma de reconhecimento da paternidade, Hélio descreve os lugares tenebrosos, íngremes e povoados de deuses terríveis por onde passa a carruagem do Sol. Essa estrutura espacial descrita apresenta similaridades com o inconsciente profundo, basc do mundo psíquico ainda não revelado.

O início do caminho é uma ladeira, tão íngreme que os cavalos às primeiras horas da manhã mal conseguem subir [...] O caminho corre no meio de monstros aterradores; passa junto aos chifres de Touro, em frente ao Sagitário e perto das faces do Leão e onde o Escorpião estende seus ferrões numa direção e o Caranguejo na outra. E verás que não é fácil guiar esses cavalos, com seus peitos repletos do fogo que
sai por suas bocas e narinas.

Quando Faetonte cobra a promessa real, seu pai é obrigado a ceder. O filho sobe na carruagem do Sol, mas, como a tarefa estava além de sua capacidade, não pode controlar a gigantesca biga, perdendo o domínio de si mesmo e dos cavalos que disparam em acelerada correria. Alastrou-se um vasto incêndio, inflamaram-se as nuvens e fenderam-se as terras; os rios evaporaram-se e animais

9 BULFINCH, Thomas. O livro de ouro da mitologia: história de deuses c

heróis. Trad. David Jardim Júnior. 4. ed. Rio de Janeiro: Ediouro, 1999, p 51.

11 p.51.

Idem p.52.

12 Idem p.53. 
sucumbiram quando Faetonte, sem saber como controlar o desgovernado carro, é coberto por uma espessa camada de fumaça, criando o Caos. A grande deusa Terra, vendo seus domínios devastados e mergulhados no escuro onde nada se produz, pede a intervenção de Zeus, que sobe ao Olimpo e de lá desfere um raio certeiro contra o impulsivo rapaz, lançando-o morto no espaço. $\mathrm{O}$ herói, tragado pelo fogo/raio do pai Zeus, cai no rio Erídano que lhe extingue as chamas.

Compreendemos pela história de Faetonte que a trajetória da individuação de João Urso (re)visita de forma quase exemplar e paradigmática, em momentos significativos do conto, o mito da orfandade.

Vivendo por muito tempo apenas com a mãe, João Urso desconhece quem é o pai. Essa colocação inicial, que está na origem do mito, já determina o problema a ser tratado: a ausência do pai e a longa permanência junto à mãe. João Urso, como Faetonte, permanece ligado ao mundo da natureza, ao instintivo, porque o pai está ausente, não somente física e psicologicamente, como também como símbolo no discurso da mãe. O pai como símbolo estruturante, que faz a mediação da saída da inconsciência dita matriarcal para a consciência dita patriarcal, inexiste no início do mito e da história da personagem.

Erich Neumann ${ }^{13}$ considera o pai um símbolo estruturante de grande importância no•desenvolvimento da personalidade, pois ele retira a criança da plenitude da indiscriminação urubórica da mãe e a coloca dentro de uma nova dimensão, que é a do pai, representação racional da lei e da ordem. O arquétipo do pai, projetado no pai carnal, é quem promove o desenvolvimento da estrutura psíquica do filho e permite a abertura para um horizonte de novas potencialidades. Neumann diz ainda que o mundo do pai é o mundo dos valores coletivos, que é histórico e diz respeito ao estado relativo do desenvolvimento da consciência e da cultura. No reino do pai, os filhos trazem a sua contribuição símbólica para o projeto evolutivo de busca da totalização, da conjunção dos opostos.

A passagem do mundo "matriarcal" e a seguida inserção e apresentação do pai pessoal (ainda sem nome, mas um rosto, uma

13 NEUMANN, Erich. História da origem da consciência. Trad. Margit Martincie. São Paulo. Cultrix, 1995. p.131. 
persona) é ameaçadora para a psique da personagem João Urso; tanto é assim que, no momento em que a mãe o apresenta ao pai, revelando aos olhos do filho a identidade paterna, o narrador visionário tece algumas considerações que apontam para a futura significação dessa personagem na trajetória da individuação de João Urso: um estranho cheio de sangue, com mãos áridas, calosas e duras, prognóstico do destino do filho. Aliás, a presença da cor vermelha, expressando um ser ensangüentado, ferido e mutilado, constitui uma imagem de ruptura e agressão recorrente na memória ensandecida da personagem, durante todos os momentos da narrativa, numa clara alusão à imagem sangrenta do pai que, de fato, fere mortalmente sua vida afetiva e psiquismo.

E um dia, ao acordar, viu a mãe dizer para um homem alto, de ombros fortes, cheio de sangue:

— Este é João Urso, seu filho!

$E$ sentiu que as mãos daquele estranho, daquele homem que sua mãe dizia ser seu pai, eram duras como pedra, encrespadas de calos. ${ }^{14}$

A passagem do mundo "matriarcal" (inconsciente) para o "patriarcal" (ego) precisa ser atraente e compensadora, uma vez que o pai, nessa etapa da individuação do filho, necessita superar o poder urubórico da mãe, para que o indivíduo faça a troca e se sinta gratificado com a transferência. O pai assume proporções grandiosas, idealizadas e onipotentes (para João Urso e Faetonte), quando apresenta, ao filho, ouro e pedrarias jamais vistas no limitado mundo da personagem: "Depois o pai levou-o para o quarto, abriu as malas de couro, canastras entupidas de riqueza. E pela primeira vez João Urso

14 p.28.

Jean Chevalier e Alain Gheerbrant, ao tratarem da simbologia do sangue, vinculam-no a todos os valores solidários com o fogo, o calor e a vida, relacionando-o com o sol e o vermelho. Ambivalentes, representam o ventre, onde a morte e a vida se transmutam uma na outra: "porque esta é, com efeito, a ambivalência deste vermelho do sangue profundo: escondido, ele é a condição da vida; espalhado, significa a morte. Por isso o interdito que atinge as mulheres menstruadas; o sangue que deitam fora é impuro, porque ao passar da noite uterina ao dia, ele inverte a sua polaridade e passa do direito ao esquerdo.". CHEVALIER, Jean \& GHEERBRANT, Alain. Dicionário de símbolos. 13. ed. Trad. Vera da Costa e Silva e outros. Rio de Janeiro: José Olympio, 1999, p.944. 
ouviu falar em diamantes, em pedras preciosas, que o pai dizia valerem uma fortuna". ${ }^{15}$

Como ocorrera a Faetonte, o filho é também ofuscado pelo brilho do esplendor do pai, pelo mundo novo, brilhante e luminoso que ele agora lhe apresenta; a grande ausência do pai real constrói na psique de João Urso a fantasia de um pai arquetípico, facilitador do seu ingresso no mundo da racionalidade, da cisão da mãe e dos limites para a construção da sua identidade. Prosseguindo no processo vital dessa transferência do matriarcado para o patriarcado, ainda semelhante a Faetonte, dirigindo o carro do Sol pelo firmamento, o pai de João Urso - que tem nos olhos o "brilho dos aventureiros" igualmente conduz o filho através de "cavalos velozes" representados no conto pelo trem (carruagem) - apresentando-lhe um mundo novo, desconhecido, encantatório, "dizendo-lhe os nomes das terras, contando histórias daquelas usinas", e mais ainda,

O braço do pai abria uma curva, como se quisesse abraçar os serrotes, filhotes de dromedário nos morros verdes.

Tal gesto parecia dizer: - Estamos longe. - Metiam a chibata, esporeavam, e os cavalos alargavam as passadas, relinchavam, as ancas molhadas de suor como se tivessem acabado de atravessar um rio. Depois, o trem do Recife correndo léguas inteiras de canavial, mostrando usinas de compridos bueiros. João Urso deslumbrava-se. ${ }^{16}$

A imagem arquetípica do Grande Pai é portanto projetada no pai carnal, para João Urso; ele é o condutor e apresentador do mundo racional e organizado, ajudando a personagem a fazer a passagem necessária, a saída do mundo instintivo da mãe para a consciência egóica. Porém, quando o filho dá os primeiros passos para romper o elo com a mãe primitiva, o brilho imutável do pai desaparece, "cobrindo-o de fumaça", e João Urso, sem força para controlar sozinho os cavalos, uma vez que o pai voltara a desaparecer, precipita-se no abismo da inconsciência, mergulhando na terrível sombra arquetípica: "E nunca mais João Urso viu canastras cheias de riquezas, aquelas canastras de

$\begin{array}{ll}15 & \text { p. } 28 . \\ 16 & \text { p. } 28 .\end{array}$ 
couro... Nunca mais sentiu as mãos calosas do pai, nunca mais ouviu falar em diamantes como seu pai falara". ${ }^{17}$

Jung considera que todo arquétipo é bipolar e que, ao lado de uma mãe ou pai bom e generoso, há igualmente um pai terrível, castrador e urubórico. Erich Neumann também diz, a esse respeito, que o caráter assustador de um arquétipo, o da Mãe Terrível, por exemplo, aparece também no arquétipo do Pai perverso e, dessa forma, considera que essa força contraditória do arquétipo desencadeia no ego modificações das suas pulsões, instintos, paixões e afetividades, instaurando o "efeito dinâmico do arquétipo determinante que desempenha um papel na enfermidade psíquica, especialmente na psicose, mas também na neurose".18

Em todo processo de individuação são necessárias a projeção e introjeção dos variados arquétipos que habitam no inconsciente coletivo; sem esse movimento de pôr para fora os elementos do grande inconsciente e o retorno ao ego depois de ordenar e constelar as polaridades como sombra e persona, Pai e Mãe, anima e animus, o indivíduo não constrói um caminho para o Self, o centro da totalidade psíquica. Jung também considera que a numinosidade do arquétipo, isto é, algo desconhecido, misterioso, volátil que surge independente da vontade consciente, é uma experiência avassaladora para o ego. $\mathrm{O}$ contato direto com o arquétipo sem a mediação da projeção que reduza o seu poder é desestruturante para qualquer indivíduo. $O$ contato direto com o pai físico, seguido de sua retirada, mutila mais um vez o filho João Urso, pois através dele João Urso havia entrado em contato com o pai arquetípico que lhe apresentara um mundo de brilho, luz, aventura. A retirada do objeto da projeção - o desaparecimento do pai - desconectou o filho do pai arquetípico, ferindo-o; como Faetonte, ele não consegue mais seguir sozinho, dirigindo a carruagem do próprio destino.

Os sentimentos de orfandade, carência e ausência do outro se intensificam agora, no João-Urso adulto; nas lembranças do passado e da mãe, que não compreendia a causa do riso inconveniente e impróprio do filho. É um riso nervoso, doentio e fantasmagórico que

17 p.29.

18 NEUMANN, Erich. A grande Mãe: um estudo fenomenológico da constituição feminina do inconsciente. Trad. Fernando Pedroza de Mattos e Maria Sílvia Mourão Neto. São Paulo: Cultrix, 1999, p.20. 
fez a mãe colocá-lo de castigo várias vezes, obrigando-o a decorar infindáveis sonetos, pois acreditava ser esse riso um sinal de insubordinação e desrespeito:

- Volte já para o banco, seu maluquinho. Mais três, ouviu?

João Urso sabia que "mais três" significavam mais três sonetos a decorar. Trepava novamente e voltava à realidade muito tempo depois, as pernas pendendo do tamborete alto.

De repente os ecos dos risos de João Urso atravessavam os corredores, enchiam o quarto, venciam a monotonia do imenso sobrado. ${ }^{19}$

\section{João Urso: o inconsciente (re)visitado}

O narrador visionário, sempre em deslocamento, fundindo passado e presente, conta a história de João Urso em flashback (o início da narrativa já apresenta a personagem solitária, aprisionada, debruçada na janela do sobrado, refletindo sobre a sua triste condição), indo buscar imagens da infância da personagem como quem sabe que é no escuro inconsciente em que estão submersas as justificativas do obscuro e inexplicável riso. Henri Bergson ${ }^{20}$ afirma que o riso oculta sempre uma segunda intenção; diz ainda que não se trata de algo concluso, mas alguma coisa que se prolonga, eco de incontáveis ressonâncias, algo começando por um estado para continuar ribombando como o trovão da montanha. De fato, ao deslocar o olhar para o passado, a personagem procura compreender qual a segunda intenção que todos na cidade vêem no riso "que tanto ele amava." Agora já adulto, solitário na janela do sobrado, vendo os trovões e relâmpagos tingirem de vermelho todos os objetos do casarão, ${ }^{21}$ repositório das imagens arquetípicas do Grande Pai e Mãe,

19 p.21-22.
20 BERGSON, Henri. $\boldsymbol{O}$ riso: ensaio sobre a significação do cômico. Trad. Nathanael C. Caixeiro. Rio de Janeiro: Zahar, 1983.

21 Sugerimos a leitura feita por Gaston Bachelard em que ele considera a casa como uma das maiores forças de integração para os pensamentos, as lembranças e os sonhos do homem. Nessa integração, o princípio de ligação é o devaneio. BACHELARD, Gaston. A poética do espaço. Trad. Antônio de Pádua Danesi. São Paulo: Martins Fontes, 1993. 
o eco desse passado ressoa no inconsciente, trazendo à superfície os fantasmas ali adormecidos, retorno retórico e psíquico ao caos primevo. Há uma relação que se estabelece no texto entre a cor vermelha dos relâmpagos e a lembrança do rosto avermelhado do pai, assim como, na narrativa mítica, Faetonte deixa todo o universo incendiado/avermelhado com seu carro de fogo.

Quando os relâmpagos mais fortes entram com uma vermelhidão pela janela, fazem doer-lhe os olhos; por um instante mostram pedaços da sala de jantar: cadeiras retratadas num espelho oval, um metro de parede preenchido por um quadro do sagrado coração de Jesus [...] $E$ quantos retratos de antepassados de João Urso ficam tingidos sangrando na luz dos relâmpagos! $!^{22}$

Motivada pela força dos relâmpagos, a memória continua trazendo de volta o tempo na impressão que o inconsciente dita: "Como o velho piano apareceu ensangüientado! Quando os relâmpagos avançam pelo lado do rio, a cristaleira parece ficar com as taças cheias de vinho, de vinho de uma estranha festa, que ninguém quis beber". ${ }^{23}$

O distanciamento cronológico seleciona os valores da realidade, as lembranças se depuram, fornecendo ao mesmo tempo imagens dispersas - retratos, cadeiras, cristaleiras, piano - e um corpo de imagens - os morroś, o casarão, a cidade - como se o inconsciente permanecesse preso também ao espaço físico em uma forma de casulo, concha da memória afetiva. A caracterização do espaço físico segue, portanto, o movimento das razões ou das desrazões de João Urso; ora a caracterização é fortíssima, hiperbólica, ora se acalma como se acompanhasse o ritmo, o volume dos gritos/gargalhadas da personagem ensandecida: "Naquela [serra], são as cores vermelhas dos relâmpagos, trovões arrebentando em gritos enormes, árvores tingindo-se rapidamente e rapidamente voltando ao verde de suas folhas". ${ }^{24}$ Esse espaço diferenciado, visto pelo olhar de João Urso, é profundamente marcado por um vocabulário de rupturas rapidamente arrebentando em gritos e rapidamente voltando à calma constituindo forte indício da sua razão mutilada: "Relâmpagos

\footnotetext{
22. p.20. Grifo nosso.

23 p. 20 .

24 p.19. Grifos nossos.
} 
retalhando serras, ensangüentando árvores, debruçando manchas sobre a cidade, manchas de amplos reflexos que são nódoas de sangue nas torres das igrejas, nos poucos sobrados, nos muros do cemitério". ${ }^{25}$ A imaginação doentia da personagem constrói cenários com sombras dantescas, sombras que representam, enquanto negatividade psíquica, o inconsciente turvo, nebuloso e desestruturado do protagonista.

A sombra arquetípica, entendida como o lado não revelado do arquétipo, contém aspectos que o ego não conscientizou e, conseqüentemente, não reconhece como seus. A introjeção da sombra exige do indivíduo uma consciência moral, fruto de um trabalho árduo de autoconhecimento, revelação muitas vezes não desejada; sem ela, não é possível o sujeito se reconhecer como totalidade, diz Jung:

A sombra constitui um problema de ordem moral que desafia a personalidade do eu como um todo, pois ninguém é capaz de tomar consciência desta realidade da sombra, trata-se de reconhecer os aspectos obscuros da personalidade, tais como existem na personalidade. Este ato é a base indispensável para qualquer tipo de autoconhecimento. ${ }^{26}$

A diferenciação do ego da totalidade original, seu crescimento e sua estabilidade constituem um processo difícil, podendo levar 0 indivíduo à morte, como ocorrera a Faetonte, ou à loucura, destino de João Urso. Encarcerado no mundo da inconsciência, solitário, desejoso de si mesmo e de outros, "quantas lembranças a memória de João Urso foi buscar, [...] pedaços do seu triste passado, quantos João Urso reviveu, quantos!",27

Nesse rememorar, João Urso se vê menino brincando com outras crianças no sótão da casa quando, inexplicavelmente, explode no riso desagregador:

As crianças começaram a chorar como se estivessem a pedir socorro. No meio do corredor, João Urso era um vulto rindo nervosamente, rindo às gargalhadas, enchendo de pavor as crianças que continuavam a

\section{p.25.}

26 JUNG, C. J. Aion: estudo sobre o simbolismo do Si-mesmo. Trad. D. Mateus Ramalho. Petrópolis: Vozes, 1982. p.6.

27 p. 30. 

chorar, chamando pelos pais, pedindo o socorro de
alguém. $^{28}$

O narrador, revelando a memória da personagem, traz para o presente ficcional o eco desse riso que toma proporções cada vez mais desconstrutoras para a psique da personagem; agora o riso sai de dentro do casarão e, como a sombra arquetípica que irrompe do inconsciente e se projeta, o riso/sombra terrível ocupa todos os espaços da consciência egóica da personagem, ampliando seus domínios e se manifestando em várias situações e lugares freqüentados por João Urso: "Mesmo que pudesse ir à igreja, não poderia segurar nenhuma lanterna. $O$ padre proibira. As beatas se encheram de jaculatórias, de sinais-da-cruz e soltaram, muitas vezes, a palavra "excomungado". ${ }^{29} \mathrm{E}$, mais adiante, sempre em um crescente, volta a lembrar o narrador: "E nas escolas, professoras diziam assim quando pegavam alguém rindo sem razão, sem ver por quê: - Será que está com a doença do João Urso? E nenhuma escola quis ensinarlhe". ${ }^{30}$ Finalmente, intensificando cada vez mais esse horizonte de cerceamento e estigma, a cidade expulsa João Urso do seu convívio:

Sant'Ana do Ipanema era uma voz que tudo transmitia, que não sabia guardar o mais sério dos segredos. Gente da redondeza soube dessa história. $E$ nas feiras, no açougue, na prefeitura, na casa das mulheres da Rua do Sebo, falavam da doença de João Urso. Imitavam-lhe as gargalhadas, rasgavam o silêncio das noites arremedando-lhe os risos. Era moda rir como ria João Urso. ${ }^{31}$

Essas atitudes de rejeição e de zombaria que as culturas de várias épocas dispensam aos loucos remetem ao que Dodds vai chamar de "cultura da vergonha", sentimento que imperou na Grécia antiga. O espírito heróico das personagens homéricas, por exemplo, não permitia que elas cometessem nenhum ato insano, o que atribuía às atitudes de loucura manifestações divinas, ficando o herói apenas como um mortal sujeito aos caprichos dos deuses. A Idade Média, por sua vez, também tinha a sua cultura da vergonha, e a saída para coibir as excentricidades

\footnotetext{
28 p.22.

29 p.23.

p. 25 .

31 p. 24.
} 
da loucura era ocultar os loucos dos olhos do mundo; esses seres considerados possessos por forças malignas recebiam o tratamento de padres exorcistas (João Urso recebe água benta, jaculatórias) que tentavam expulsar o demônio do corpo do possuído. Além das orações e rituais, os loucos também eram expulsos da cidade ou enclausurados em porões e casas de detenções pelo medo, pavor e repugnância que provocavam. Na narrativa, o estigma se repete; João Urso é mantido por cinco anos no asilo, longe da mãe, "cinco anos de natal despercebido, ausente das vésperas de São João" "32 da cidade que amava, do sobrado da infância. Ao retornar depois de várias medidas médicas fracassadas como a sugestão dada para respirar manso, tomar ar puro das serras, depois de especialistas se terem reunido em junta médica e ouvido colegas renomados da Europa, João Urso volta rindo cada vez mais, soltando gargalhadas, urros inexplicáveis como um urso que, estando hibernando na caverna escura, fosse despertado de um sono letárgico e se encolerizasse. A nosso ver, o insucesso do tratamento médico reforça a idéia de que é no desarranjo psíquico que se situa a causa do riso doentio de João Urso.

Agora, João Urso voltava. Viu a mãe trinta anos mais velha, escutou quase silencioso aquele coração que dantes batia forte. Sentiu comoção, uma vontade imperiosa de chorar, de abraçar a mãe aos soluços. Abriu os braços, enlaçou o peito da mãe num violento aperto, e começou a rir-se, a rir-se como nunca havia rido, um riso doente, entrecortado de gritos profundos, de alucinantes gargalhadas.

Henri Bergson, tratando o riso, entre outros aspectos, como uma forma de castigo que pune o que é risível, chama a atenção para o fato de que, para alguém suscitar o riso, ele não pode apresentar loucura ou idéia fixa, como é o caso de D. Quixote, uma vez que "nem a loucura em geral nem a idéia fixa nos fará rir, porque se tratam de enfermidades. Elas suscitam a nossa piedade.[...] Se há uma loucura risível, só pode ser uma loucura conciliável com a saúde geral do espírito, uma loucura normal por assim dizer". "Essa loucura normal de que fala Bergson é o que falta a João Urso. Seu riso não manifesta excentricidade, gozo ou prazer - ele ri quando deseja chorar - mas a

\footnotetext{
32 p.27.

33 p.29. Grifo do autor.

34 Idem, p.95.
} 
manifestação doentia, contraditória e incontrolável de um inconsciente mergulhado na sombra patológica. Contrariamente ao que Bergson coloca, não é compaixão ou piedade que os habitantes da cidade sentem pelo louco que gargalha; o maior drama da personagem é o estigma e a conseqüente solidão em que vive, marcado por um forte vazio existencial: "João Urso se vê órfão de mãe, esquecido do pai que há tanto não dava notícia, talvez morto, ou morrendo naquela riqueza de que o povo falava". ${ }^{35}$ Vivendo isolado no velho casarão, após a morte da mãe, banido de qualquer convívio humano, impossibilitado de se relacionar com os outros, só resta ao "urso" a caverna escura das noites solitárias

Vivendo como um bicho que ama as madrugadas, o ermo das ruas adormecidas. E João Urso sentia-se feliz quando algum tresnoitado dava-Ihe boa noite, pedia-Ihe fósforo. E era com o olhar cheio de saudade que ele via o vulto se afastar. E também João Urso se afastava, temendo ser reconhecido, medroso de ver o tresnoitado fugir às carreiras, distanciar-se cheio de pavor ao descobrir que ele era João Urso. ${ }^{36}$

Finalmente, a última e fatal imagem rememorada leva João Urso a um circo que chega à cidade, onde é outra vez atraído por elementos brilhantes - "as luzes do circo pareciam chamá-lo: eram apelos." Deslumbrado com as luzes, João Urso chega ao circo no instante em que uma bailarina se equilibra em um trapézio; faz-se, então, um grande silêncio, e o tocador do bombo aguarda o desenlace.

E no momento do salto, quando os pés da bailarina voaram feito duas asas de lantejoulas, de estreitas calças de cetim vermelho, de um porta-seios robusto, neste momento João Urso soltou um agudo de um riso estrangulado, cortante, talvez o maior riso de sua vida. E a bailarina pareceu um pássaro ferido, um vôo que tombava. ${ }^{37}$

Mais uma vez, a cor vermelha reforça a confusão psíquica que se opera na mente da persona; o vermelho/sangue com que os relâmpagos ferem os morros e a cidade chega a João Urso: "agora ele

p.30.

p.30-31.

p.32. Grifos nossos. 
é somente tingido pelos relâmpagos". O vermelho, que os relâmpagos tingem, simboliza, ao mesmo tempo, a roupa de "cetim vermelho" da bailarina, o "riso estrangulado, cortante", ferindo mortalmente a equilibrista e o pai "cheio de sangue" sempre ausente desde a infância, mutilando-o, pois cortou a possibilidade de o filho construir um caminho que o levasse à conquista da própria individuação.

No momento final do conto, João Urso permanece prisioneiro no sobrado, encarcerado pela rejeição dos populares que lhe atiram pedras, quebrando os vidros da casa, gritando de punhos erguidos como a querer linchá-lo pela morte da bailarina. O delegado coloca soldados armados à porta do casarão, e a ordem era: “- Se esse renegado tentar fugir, já sabem: fogo". ${ }^{38} \mathrm{E}$, qual Faetonte depois que o fogo do carro paterno incendiou todo o universo, - "Mais uma vez João Urso ensangüentava os olhos nos relâmpagos" - ${ }^{39}$ João Urso sabe que não tem mais como superar o caos em que sua vida mergulhara e, portanto, seu único desejo agora é "dormir esperando uma partida para muito longe, uma viagem que nem ele próprio sabe aonde terminar". ${ }^{40}$ Solidão, abandono e o grande riso como manifestação insana da dor silenciam para sempre o louco que chora gargalhando: "procura a cama, fecha os olhos, guardando dentro deles geografia incomum das constelações, a matemática dos termômetros amigos, o belo vôo incerto da bailarina...". 41

\section{Conclusão}

Pela leitura do conto João Urso, vimos que, na escrita de Breno Accioly, o arquétipo do louco se transformou numa resposta poéticoexistencial, espécie de solução macabra e perversa que o ficcionista encontrou para representar o drama existencial e psíquico que marcou a vida da personagem João Urso em crescente decomposição mental. Marcada pela imagem do louco a que o senso comum nega qualquer sentido positivo, prazeroso ou heróico, a personagem acciolyana ratifica e intensifica, pela força estilística, a visão cultural pejorativa desse arquétipo. Mesmo com significativos avanços na área da psicologia, concluímos que a visão da loucura como algo repulsivo,

\footnotetext{
38 p.31.

39) p.32.

40 p. 33 .

41 p.33.
} 
tenebroso e demoníaco ainda não se distanciou significativamente, por exemplo, da visão de possessão da Antigüidade Clássica. O arquétipo do louco, interpretado como negatividade e desestruturação, permanece vivo, de forma inquietante e inquietadora, o que possibilitou a Breno Accioly construir um texto de atmosfera tensa e fantasmagórica. Impossibilitado de ordenar de forma psíquica os traumas da personagem criada, sua ficção representa o espaço privilegiado de ordenação poética do caos, pois, ao ficcionalizar a psique, o escritor buscou ordenar a desordem psíquica via escritura.

Sua palavra poética se tornou, então, reveladora da angústia humana nunca resolvida e uma válvula de escape melancólica, concretizada em um texto em que a personagem, sufocada pela força do inconsciente profundo, projeta no mundo circundante os fantasmas adormecidos na memória. O desejo de ver esse inconsciente revelado na criação mitopoética da escritura simbolizou um voltar-se da obra sobre si mesma, em uma tentativa de que ela se desnude e, em se desnudando, apresente também um inconsciente necessitado de ser projetado e revelado. O desespero e a solidão são fundamentalmente elementos componentes na escrita de uma tristeza desmedida, que se transformou, pela intensidade e frequiência, na representação de uma insanidade paradoxalmente privilegiada. A solidão ficcional, que é a tônica da vida da personagem, aguçou a percepção desse ser perturbado, fazendo com que o sentido do ver e fazer no texto, como no mundo ficcional, circulasse em um tempo e espaço que são inconscientes fora do tempo e do espaço ditos racionais.

Um aspecto observado na leitura do conto e que constituiu o ponto de partida da nossa hipótese foi a idéia defendida por Jung de que nos arquétipos encontraríamos a gênese do processo criador. Essa afirmação percorreu toda a leitura que fizemos da narrativa e comprovamos como a presença de vários arquétipos apareceu na ficção como dados sempre presentes do inconsciente que se materializaram como metáfora/símbolo na escritura de Breno Accioly. Vimos, portanto, que a interpenetração do plano da teoria junguiana com o plano da criação literária efetiva-se, de modo a não deixar dúvidas, no conto estudado. Entre os diversos mitos e arquétipos representados no discurso, o do pai terrível, perverso e urubórico e, especialmente, a grande Sombra Negativa constituíram o tema da ficção estudada. 
Incapaz de discriminar os vários símbolos arquetípicos, de constelar os pares opostos e necessariamente complementares para o processo de individuação, a personagem João Urso, como na narrativa mítica de Faetonte, desconhece o caminho por que deveria passar com sua biga, não encontrando forças para dirigir a carruagem do Sol; desequilibrada, cai no precipício sufocada pela fumaça escura, incêndio da psique que cobre toda a vida, tragada pela força instintiva do inconsciente profundo onde o ego permanece indiscriminado, em um trajeto nunca concluído.

A narrativa de Breno não teve, no interior da fábula, uma linearidade cronológica ou espacial; o ato narrado ou o drama no momento vivenciado pela personagem foi sempre uma retrospectiva atualizada no tecido romanesco dos traumas, desencontros, sofrimentos e rejeições vividas no passado e que resultaram nas loucuras cometidas por João Urso. Esse recurso à memória, largamente utilizado pelo narrador onisciente, constitui uma descoberta significativa para a leitura de base junguiana que empreendemos.

Consideramos, ainda, que essa opção narrativa que Breno Accioly usou com muita propriedade levou-nos a duas conclusões: a primeira delas é que, do ponto de vista narrativo, tal processo possibilitou ao narrador intruso e invasivo, deslocar-se do presente para o passado da personagem, esclarecendo e justificando as atitudes descontroladas da personagem. A segunda conclusão nos permitiu entender que, compondo uma narrativa de feição visionária, estranha e perturbadora, a opção autoral de Breno Accioly é uma representação discursiva do desejo de revelar o inconsciente profundo, buscando o ponto de partida, fio de um novelo que a memória da personagem estudada representa. Buscar na escrita esse fio da meada é retornar ao lugar onde tudo ainda é incerto, amorfo e informe - o grande inconsciente - necessitando iniciar um processo de construção do ego que infelizmente a personagem João Urso não conseguiu concluir. 


\section{REFERÊNCIAS BIBLIOGRÁFICAS}

ACCIOLY, Breno. João Urso. 4.ed. Rio de Janeiro: Civilização Brasileira, 1995.

BACHELARD, Gaston. A poética do espaço. Trad. Antônio de Pádua Danesi. São Paulo: Martins Fontes, 1993.

BERGSON,Henri. O riso: ensaio sobre a significação do cômico. Trad. Nathanael C. Caixeiro. Rio de Janeiro: Zahar, 1983.

BULFINCH, Thomas. O livro de ouro da mitologia: história de deuses e heróis. Trad. David Jardim Júnior. 4. ed. Rio de Janeiro: Ediouro, 1999.

CHEVAlIER, Jeam \& GHEERBRANT, Alain. Dicionário de símbolos. 13. ed. Trad. Vera da Costa e Silva e outros. Rio de Janeiro: José Olympio, 1999.

JUNG, C. G. Aion: estudo sobre o simbolismo do Si-mesmo. Trad. D. Mateus Ramalho. Petrópolis: Vozes, 1982.

JUNG, C. G. O espírito na arte e na ciência. Trad. Dora Ferreira da Silva e Rubem Siqueira Bianchi. Petrópolis: Vozes, 1985.

NEUMANN, Erich. História da origem da consciência. Trad. Margit Martincie. São Paulo. Cultrix, 1995.

NEUMANN, Erich. A grande Mãe: um estudo fenomenológico da constituição feminina do inconsciente. Trad. Fernando Pedroza de Mattos e Maria Sílvia Mourão Neto. São Paulo: Cultrix, 1999. 